\title{
Measurement and Model Construction of Tourism Industry and Cultural Industry's Interactive Convergence
}

\author{
Haiyan Zhu ${ }^{1,2}$ \\ ${ }^{1}$ College of Tourism and Environment, Shaanxi Normal University, Xi'an Shaanxi, 710127 \\ ${ }^{2}$ Yulin University, Yulin, Shaanxi, 719000 \\ Project: Soft Science Research Projects, Shaanxi Department of Science and Technology \\ Project NO. 2015KRM166
}

Keywords: Tourism Industry; Cultural Industry; Model; Convergence Degree

\begin{abstract}
It is easy for tourism industry and cultural industry to converge with each other due to their common cultural and economic attributes. This paper builds the convergence model of tourism industry and cultural industry based on the review of the literature. And it estimates and compares the convergence degree during tourism industries converge with cultural industries based on 2007 input-output table. The results show that the convergence degree of tourism industry's initiative convergence with cultural core industries is higher than it with cultural-related industries. The convergence degree of lodging industry and restaurant industry's initiative convergence with cultural industry is higher than travel industry's initiative convergence with cultural industry. In the interactive convergence of tourism industries and cultural industries, tourism industry in most sectors leads the cultural industry in the industry integration. Accordingly this paper puts forward relevant policy recommendations.
\end{abstract}

\section{Introduction}

Tourism industry is a "Pan industry" which is different from other industry, it is rich in content and broad in extension [1]. The traditional industries are defined based on supply and therefore have a clear industry boundaries. Tourism industry is defined based on demand, and travel demand is not static, resulting in the tourism industry are not clear boundaries and with changes in demand and continuous change. Therefore, the tourism industry is a different from the traditional industries borderless industry. No border is characterized by constant change and extension and we are inextricably linked between many industries. These features make it easy to integrate into the tourism industry to other industries, and constantly derived new industry [1].

As cultural industries, Property tourism industry is strong economic and cultural industries, but also the economy strong cultural industries [2]. Common economic and cultural attributes make Relational tourism industry and cultural industries are high. Cultural industries through its cultural elements into tourism development among industry and enhance the connotation of tourism resources, rich tourism products of the type that the tourism industry has been a new development.

Common property industry the fusion of the tourism industry and cultural industry has become an inevitable trend, at the same time, state and local government attention for the development of cultural industries and the integration of the tourism industry provides a strategic opportunity. "Twelve Five" period, the development orientation of the tourism industry and cultural industries are a strategic pillar industry, the integration of the development of the two industries is as relevant national policy planning is an important strategic issues. In recent years, local governments have also be included in integrated development of the tourism industry and cultural industries to the planning and construction of the ground. Strong integration of tourism resources in Hubei province, build "western Hubei ecological and cultural tourism circle", and the introduction of the "2009-2020 Western Hubei ecological and cultural tourism circle of development planning." After the Sichuan earthquake recovery in tourism, cultural tourism is taken as its development direction. 2010, 2011, Hunan and Yunnan provinces have set up cultural tourism industry development fund. The tourism industry and cultural industries interact integration development in China will usher in the climax, 
but its interactive integration measure on the tourism industry and cultural industries in the degree of integration is more driven by the tourism industry and cultural industries to drive more integration or cultural industries Tourism industry convergence are now more ambiguous in the theory and practice problems. Therefore, the tourism industry based on analysis of fusion theory, the tourism industry and cultural industries to build interactive fusion model, while the measure of its degree of integration interaction, determine the integration process driven industries.

\section{The Tourism Industry and Cultural Industries Summary of Fusion}

Foreign scholars mainly based on heritage resources from different stakeholders or to cultural tourism development in different regions were analyzed, there is little mention of cultural tourism studies or from the perspective of industrial integration of cultural tourism were discussed. In recent years, the theory of domestic research on cultural tourism is gradually increasing, mainly focused on the development of cultural tourism resources, product development or a regional cultural tourism analysis, while the tourism industry and cultural industries from the perspective of fusion research, domestic The current achievements are still small. Studies of existing tourism industry and cultural industries for integration mainly elaborated on the fusion process, the path, summarized the integration mode, integration and development of recommendations, literature analysis typically shown in Table 1. Judging from the research method basically qualitative analysis, combined with the specific part of the study area for the tourism industry and cultural industries to discuss integration. Yangwei Wu, Xunai Qing (2012) for Shanghai tourism and cultural products in shopping Features conducted a survey, the demand from the consumer's point of view, Shanghai tourism cultural products to be quantified [3]. Fusion mode for the tourism industry and cultural industry analysis, research results more from a different perspective on the integration mode for the corresponding elaboration. Studies from the tourism industry and cultural industries to fusion model, but also from the tourism industry and cultural industries to the integration of pattern analysis, however, most scholars study for interaction between the two industries converged elaborated and summarized. Research perspective, there is the perspective of industry chain analysis, that the integration of interactive performance for both industry penetration and extend the industrial chain and restructuring industry functions. Some scholars of the tourism industry and cultural industries interactive model of integration implementations or success stories summarized.

In summary, the tourism industry and cultural industries interact with fusion research, qualitative or a combination of specific regions of the case analysis more quantitative research is extremely rare. Interactive fusion mode for more research, there are some fusion research to build an interactive model between the two industries. However, the existing model of integration and interaction models lack of initiative on the process of cultural tourism industry and cultural industries industrial integration initiative for the integration of the tourism industry and the results of the definition and analysis. Interactive tourism industry and cultural industries in the integration of research just to analyze its mutual promotion and common development of the fusion phenomenon is clearly not enough. Interactive fusion and driving still need further discussion and in-depth analysis of the impact of industry on another industry fusion produced. Therefore, based on the existing literature on the tourism industry and cultural industries to build interaction and fusion model, try to interact with the fusion industry to another industry initiative fusion approach and results defined. 
Table 1 The tourism industry and cultural industry convergence representative literature content analysis

\begin{tabular}{|c|c|c|c|}
\hline Author & Method & Module & Content Analysis \\
\hline Hu Jun(2012) & Qualitative & Cultural content into tourism & \multirow[b]{2}{*}{$\begin{array}{l}\text { From one industry to another } \\
\text { industry fusion in one } \\
\text { direction for analysis }\end{array}$} \\
\hline $\begin{array}{l}\text { Huang Xijia, Zhou } \\
\text { Qing(2012) }\end{array}$ & Qualitative & $\begin{array}{l}\text { Tourism development based on } \\
\text { cultural resources, } \\
\text { experience-based, reproduction } \\
\text { and creative fusion type }\end{array}$ & \\
\hline $\begin{array}{l}\text { Zhang Haiyan, } \\
\text { Wang } \\
\text { Zhongyun(2010) }\end{array}$ & Qualitative & $\begin{array}{l}\text { Interactive fusion mechanism } \\
\text { constructed two industries }\end{array}$ & \multirow{2}{*}{$\begin{array}{l}\text { Fusion model of interaction } \\
\text { described only enhance the } \\
\text { penetration and effect of } \\
\text { tourism on culture and } \\
\text { cultural cause and diffusion } \\
\text { effect on tourism }\end{array}$} \\
\hline Zhao Lei(2012) & $\begin{array}{l}\text { Qualitative, case } \\
\text { analysis (Taihu) }\end{array}$ & Interactive fusion & \\
\hline $\begin{array}{l}\text { Yuan Jun, Liu } \\
\text { Jianhui(2011) } \\
\quad \text { (2011) }\end{array}$ & $\begin{array}{l}\text { Qualitative, case } \\
\text { analysis } \\
\text { (Shenzhen) }\end{array}$ & $\begin{array}{l}\text { Interaction of the basic model: } \\
\text { new tourism products; cultural } \\
\text { attractions of industry; industry } \\
\text { linkage of new tourism marketing; }\end{array}$ & $\begin{array}{l}\text { Construction of the integrated } \\
\text { model of interactive tourism } \\
\text { industry and cultural } \\
\text { industries in some sectors, } \\
\text { and the results will be } \\
\text { described fusion }\end{array}$ \\
\hline $\begin{array}{l}\text { Cheng Xiaoli, Zhu } \\
\text { Yawen(2012) }\end{array}$ & $\begin{array}{l}\text { Qualitative, case } \\
\text { analysis (Anhui) }\end{array}$ & $\begin{array}{l}\text { Permeable: cultural blend into } \\
\text { tourism products; tourism function } \\
\text { given to cultural industries } \\
\text { Extended: chain extending mutual } \\
\text { Recombinant type: new } \\
\text { fusion-based industries }\end{array}$ & $\begin{array}{l}\text { Perspective of industry chain } \\
\text { integration process of } \\
\text { interaction analysis }\end{array}$ \\
\hline $\begin{array}{l}\text { Zhang Haiyan, } \\
\text { Wang } \\
\text { Zhongyun(2013) }\end{array}$ & Qualitative & $\begin{array}{l}\text { Cultural tourism circle Fusion } \\
\text { operational; fusion project } \\
\text { development operations; cultural } \\
\text { tourism festival and exhibition } \\
\text { promotion; cultural tourism } \\
\text { product innovation }\end{array}$ & $\begin{array}{l}\text { Analyze the specific } \\
\text { implementation of interactive } \\
\text { integration }\end{array}$ \\
\hline $\begin{array}{l}\text { Yang Weiwu, Xu } \\
\text { Naiqin(2012) }\end{array}$ & Quantitative & Non & $\begin{array}{l}\text { Tourism and Culture } \\
\text { questionnaires products } \\
\text { purchased }\end{array}$ \\
\hline
\end{tabular}

Source: According to reference [3] and [11]

\section{The Tourism Industry and Cultural Industries Interact with Fusion Model}

The concept model is a qualitative model is a prototype of things abstraction and generalization, enabling the study intuitive and simplified, easy to understand and spread [10]. Tourism industry and cultural industry interaction model constructed in this paper (Fig. 1), through the analysis of the interactive fusion of different active integration industry, a clear result of the tourism industry and cultural industries active fusion results for the tourism industry and cultural industries active integration.

Interactive tourism industry and cultural industry convergence refers to the tourism industry by giving cultural industries to tourism function, changing the culture industry chain of the process, while the tourism industry and cultural industries by giving cultural functions, improve the process of the tourism industry chain related links. Interactive fusion process, the tourism industry and cultural industries to impart functional integration of tourism industry initiative called for the integration of the cultural industry, tourism industry and cultural industries to impart cultural integration feature called cultural industry initiative for the integration of the tourism industry. Effects of different industry leading model of integration bring fusion industry. Integration of the tourism industry to take the initiative to change the cultural industry cultural industry chain 
functions, such as the original site of class resources, through tourism functions conferred its development, thus becoming the ruins class tourism products, and consumers face mainly tourists. Cultural industries to take the initiative to enhance the integration of the tourism industry value chain of the tourism industry, there has been integrated into the cultural function of tourism resources, tourism products - such as the United States Disneyland by the virtual reality scene cartoon landscape, giving visitors a whole new experience, live performance impressed the great success of the series has changed the traditional tourism product life cycle.

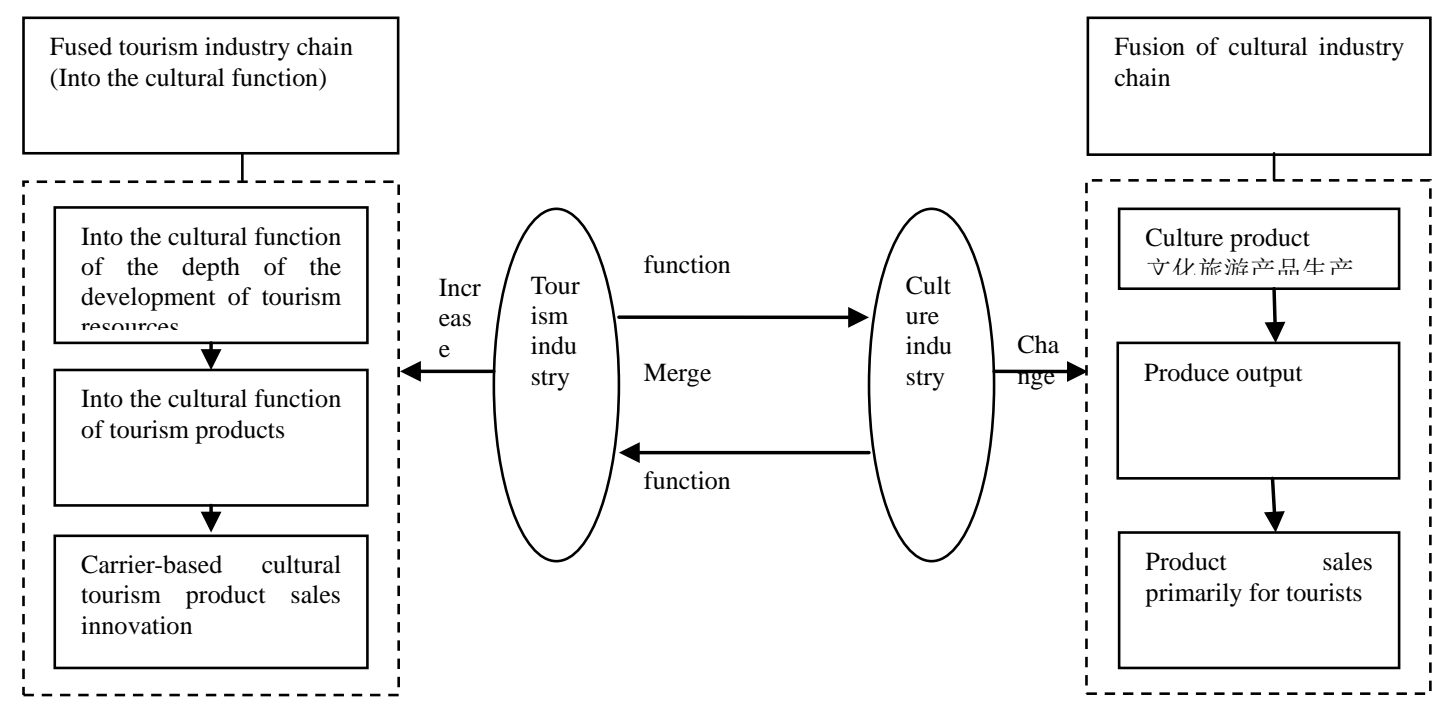

Fig. 1 The tourism industry and cultural industries interact fusion model

\section{The tourism industry and cultural industries confluence estimates}

Interactive fusion model is the current tourism industry and cultural industry interaction model of integration of in-depth analysis, and industry interaction can not explain two specific integration practices to drive the industry. Therefore, in order to further illustrate the fusion of two industry interaction practice in the tourism industry which industries led the integration of the cultural industries and cultural industries led the industry in which the fusion tourism industry, the paper industry, the integration of the tourism industry and cultural industries will be the industry measurement and comparison.

Research Method. Industry convergence phenomenon is still in its early stages of development, so the fusion result - a new industry or innovation related data is difficult to obtain, there is no one to build a degree of integration of industry metrics and measurement methods. Existing studies, scholars mainly take the following three kinds of methods to try to carry out industrial integration measure: Fai and Tunzelmann (200l) using the correlation coefficient between the estimates of the US patent industry chemical, electronics, machinery and transport four industry technical integration of interdepartmental [11]. Li Feng, Chen Taizheng et al. (2013) with a Herfindahl index measured the degree of integration of technology integration of the tourism industry, business integration, market integration of R \& D expenditure and R \& D personnel [12]. Xu Ying, the Sun Jian (2009) Application of input-output analysis to calculate the degree of integration of manufacturing and information industries [13]. The above-mentioned three methods, the first two methods measure is mainly aimed at the integration of technology convergence in the measurement industry, Herfindahl index, such as market integration, business integration and other estimates reflected in the degree of integration of technology integration is still I thought, and primarily measure the degree of integration of the tourism industry, other industries active integration. Interactive tourism industry and cultural industries fusion is not just the tourism industry, the integration of the cultural industry, tourism industry, but also reflects the cultural industry penetration, so this method is not suitable for measuring the degree of integration of tourism and cultural industries are. Input-output analysis reflects the interactive relationship between the two 
industries, and therefore more suitable for the tourism industry and cultural industries interact with a fusion of the measure.

Based on the above considerations, the paper draw input-output method and degree of integration of the tourism industry and cultural industries were measure. This calculation method, although underestimated the degree of integration of information industry and manufacturing to some extent, but the overall trend point of view, then there will not be much impact. To highlight the tourism industry and cultural industries to drive the integration of the tourism industry and cultural industries to drive the integration of different, the calculation method of the degree of integration has made the appropriate changes. The tourism industry in the cultural industry investment and the amount of the proportion of people in its total output in the industry as a cultural initiative for integration of the tourism industry, the integration of the measurement index, the cultural industry investment in the tourism industry in the proportion of its total output volume as the tourism industry to the integration of the cultural industry integration initiative measure indicators. Specific formula is as follows:

Tourism industry initiative fusion of cultural industries Fusion $B_{i} A_{j}=B_{i} / A_{j}$ (1)

Where $\mathrm{Bi}$ represents the middle of the tourism industry in the cultural industries sector $\mathrm{i} j$ industry investment, $\mathrm{Aj}$ represents the cultural industry in the total output of industry j.

Tourism industry $\mathrm{i}$ in the cultural industry initiative for the integration of fusion ( $\mathrm{n}$ is the total number of cultural industries in the industry) $B i A=\sum_{j=1}^{n} B_{i} A_{j}$

I take the initiative in the cultural industry sector in the tourism industry a fusion of industry j $A_{i} B_{j}=A_{i} / B_{j}$

Where $\mathrm{Ai}$ represents the cultural industry in the middle sector of the tourism industry $\mathrm{i} j$ investment, $\mathrm{Bj}$ represents the tourism industry in the total output of industry $\mathrm{j}$.

I cultural industries sector initiative for integration of tourism industry convergence ( $\mathrm{n}$ is the total number of tourism industry in the industry) $A_{i} B=\sum_{j=1}^{n} A_{i} B_{j}$

As $B_{i} A_{j}>A_{i} B_{j}$ described tourism industry industry initiative driven cultural industries $\mathrm{i} j$ industry convergence trend is obvious; when $B_{i} A_{j}<A_{i} B_{j}$, indicating the cultural industries sector initiative to promote tourism industry $\mathrm{i} j$ industry convergence trend is obvious; when $B_{i} A_{j}=A_{i} B_{j}$, indicating the cultural industry in various industries and tourism industry interactive integration of various industries, the two sectors of the same drive.

In this paper, data from the 2007 input-output table, as the annual data are not on the cultural industry statistics, only statistics for various industries, Therefore, in accordance with "cultural and related industry classification" standard promulgated by the National Bureau of Statistics in 2004 in Ministries class cultural industries to extract data in various industries. Culture Core industries include 2007135 sector input-output table of handicrafts and other manufacturing (A1), telecommunications, and other information Transmission Services (A2), computer services (A3), technology exchange and promotion services (A4) News Publishing Industry (A5), radio, television, film and video industry (A6), arts and culture industry (A7) and entertainment (A8), culture-related industries category include paper and paper products industry (A9), the printing industry and reproduction of recorded media industry (A10), Sporting Goods Manufacturing (A11), paint, ink, paint and similar industrial manufacturing (A12) and culture, office machinery manufacturing (A13). Tourism adopted a narrow definition, the input-output table in the lodging industry (B1), catering (B2) and tourism (B3) (B3 mainly refers to the travel industry) classified as a tourism article (B) category. The following section describes in the letter instead of various industries.

Data Analysis. 1 and 2 according to the formula calculated various sectors of the tourism industry and cultural industries to drive the integration of various sectors as shown in Table 2. Table 2 shows data driven cultural industries in the lodging industry A6 industry a higher degree of convergence, reached $3.11 \%$, followed by A3 industry, the fusion of $1.73 \%$. Cater driven cultural 
industries in the A6 at the highest degree of integration fusion of $2.59 \%$, followed by A7. Travel industry driven by the higher degree of integration A8 fusion, was $1.39 \%$. From a tourism point of view of the industry, the integration of tourism and A6 are among the highest, reaching 6.13\%. In recent years, with the development of film tourism, digital on-demand TV in the lodging industry and the popularity of computer services in the application instructions tourism-led cultural tourism industry in that part of the integration industry has made great success. Hengdian Group, led by tourism film base are fused, forming a film tourism, film shooting as the mainstay of large enterprise groups, built Asia's largest film base, and became the first "4A level national tourism zone." Currently the major hotels in Xi'an, the hotel's stage performances, ritual performances, or tea ceremony performances, almost all of the energy and tourism combined performances in Mining "Tang" Culture and constantly innovative fine performance repertoire, improve the artistic content, so "Don Dance" series of fine more refined.

Driven by the level of integration of the various sectors of the cultural industry (Figure 2) from various sectors of the tourism industry can be seen in the core of the tourism industry and cultural industries to drive a high degree of integration of convergence, driven by the integration of culture-related industries are more low. Cultural industry is the main core of the cultural industry, and culture-related industries but complementary cultural industries and the former cultural function was significantly stronger than the latter. Therefore, tourism industry driven culture fusion core industries produce cultural tourism product more attractive to tourists, its higher degree of integration. From various sectors of the tourism industry, the fusion of the travel industry and the cultural industry is low, and catering and accommodation industry and the integration of the cultural industry is high. Cultural industries catering industry integration degree A7-A13 were lower than the fusion of the lodging industry and the portion of the industry. The main function of the travel industry is on the tourist route design and sales, and therefore a lower degree of integration and cultural industry. Catering and accommodation industry is important in order to enhance the market competitiveness of their products. We need to constantly and cultural industry convergence, in order to develop a more cultural type of tourism products.

Table 2 Tourism industry and cultural industries to drive the integration of fusion Unit: \%

\begin{tabular}{|l|l|l|l|l|l|l|l|l|l|l|l|l|l|}
\hline$B_{i} A_{j}$ & A1 & A2 & A3 & A4 & A5 & A6 & A7 & A8 & A9 & A10 & A11 & A12 & A13 \\
\hline B1 & 0.19 & 0.29 & 1.73 & 1.67 & 0.91 & 3.11 & 1.58 & 0.34 & 0.10 & 0.14 & 0.14 & 0.24 & 0.13 \\
\hline B2 & 0.46 & 0.65 & 1.44 & 1.55 & 1.62 & 2.59 & 2.54 & 2.07 & 0.31 & 0.49 & 0.31 & 0.60 & 0.18 \\
\hline B3 & 0.01 & 0.44 & 0.73 & 0.11 & 0.36 & 0.43 & 0.43 & 1.39 & 0.02 & 0.03 & 0.02 & 0.06 & 0.01 \\
\hline B & 0.67 & 1.39 & 3.90 & 3.34 & 2.89 & 6.13 & 4.55 & 3.79 & 0.42 & 0.66 & 0.47 & 0.90 & 0.32 \\
\hline
\end{tabular}

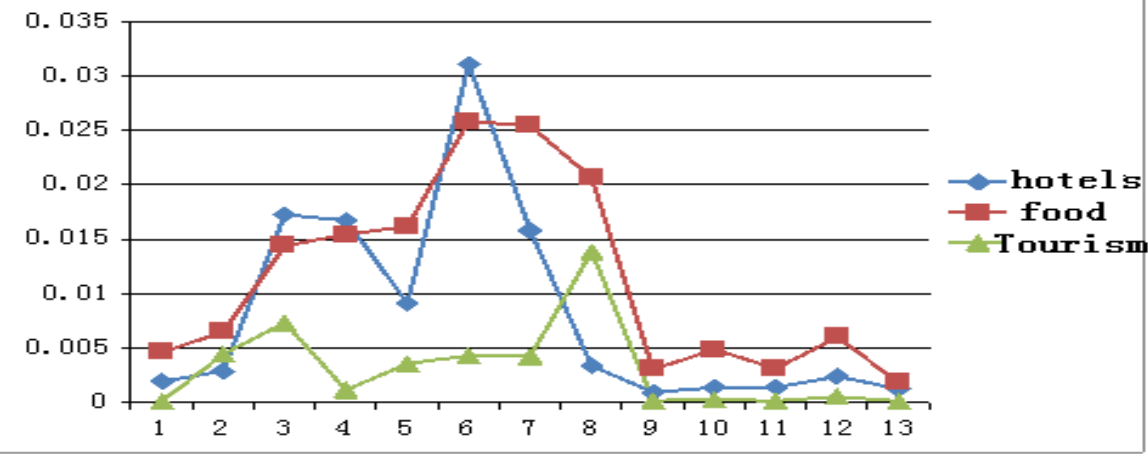

Fig. 2 Various sectors of the tourism industry and cultural industries to drive the industry level of integration

Table 3 shows the data, the cultural industry in telecommunications and other information Transmission Services (A2) drive the lodging industry at the highest degree of integration of integration, reaching 1.426 percent, followed by the fusion between the radio, television, film and audiovisual industry and the lodging industry degree, was $0.655 \%$. Integration of other cultures Industries in all sectors of the tourism industry driven are low. From the cultural industry as a whole, driven by the highest degree of integration of the cultural industry convergence lodging industry, reaching 3.464 percent, followed by the travel industry, was 1.215 percent, the lowest degree of 
integration is the restaurant industry, is only $0.725 \%$. With the popularity of Internet applications, the lodging industry in order to better meet the needs of tourists, continuous development of business rooms, wireless WIFI covering hotels and other new features into the cultural tourism products.

Table 3 Cultural tourism industry led a fusion of industries Unit: \%

\begin{tabular}{|l|l|l|l|l|l|l|l|}
\hline AiBj & B1 & B2 & B3 & Ai Bj & B1 & B2 & B3 \\
\hline A1 & 0.046 & 0.090 & 0.025 & A8 & 0.285 & 0.068 & 0.363 \\
\hline A2 & 1.426 & 0.117 & 0.136 & A9 & 0.529 & 0.311 & 0.003 \\
\hline A3 & 0.035 & 0.015 & 0.002 & A10 & 0.148 & 0.037 & 0.329 \\
\hline A4 & 0.008 & 0.001 & 0.000 & A11 & 0.066 & 0.032 & 0.014 \\
\hline A5 & 0.241 & 0.032 & 0.271 & A12 & 0.000 & 0.000 & 0.003 \\
\hline A6 & 0.655 & 0.009 & 0.028 & A13 & 0.010 & 0.002 & 0.032 \\
\hline A7 & 0.014 & 0.012 & 0.010 & A & 3.464 & 0.725 & 1.215 \\
\hline
\end{tabular}

From the comparison of $\mathrm{Bj}$ and $\mathrm{AiBj} 3$ Table 2 and table it can be found in all sectors of the tourism industry led all sectors of the cultural industry convergence trend more obvious. Cultural industries led to only a few sectors of the tourism industry fusion, including A2, A9, A10 drive the lodging industry (B1) integration, A9 led B2 (catering) integration, A1, A10 and A13 drive B3 (travel industry) integration.

\section{Conclusion and Suggestion}

Conclusion. Active tourism industry and integration of cultural industry refers to the tourism industry by giving cultural industries to tourism functions, in order to achieve integration and cultural industries. Cultural industries cultural property is to meet the needs of tourists' important attributes, functions conferred by tourism, cultural property passed to the tourists better, so as to achieve better fusion effect. Cultural core is the production of cultural products of the industry, and culture-related industries are the production of culture-related products industries, so the cultural industries in the cultural attributes than culture-related industries in the cultural attributes. Therefore, the tourism industry and cultural industries are integration initiative, to core industries and cultural integration.

Travel agency owners to refer to a business, group and individual travel service for the community. Its proactive integration and cultural industries, it is difficult given the appropriate tourism function of cultural industries, so its degree of integration and active cultural industries is low. Accommodation and catering industry and culture through a combination of industry, not only to enhance the meaning of their products, while increasing the visibility, to better attract tourists.

The traditional industries are defined based on supply and therefore have a clear industry boundaries. The tourism industry is defined based on demand, and travel demand is not static, thus resulting in the tourism industry are not clear boundaries and with changes in demand and continuous change. Therefore, the tourism industry is a different from the traditional industries borderless industry. No border is characterized by constant change and extension and we are inextricably linked between many industries. These features make it easy to integrate into the tourism industry to other industries, and constantly derived new industry [1]. Meanwhile, the tourism industry is demand-oriented industries, their needs change will bring a series of changes in the industrial chain, so as to promote the integration process of the tourism industry and other industries. Currently, pursuit of cultural tourism industry initiative promotes the integration and cultural industries. Therefore, in the tourism industry and cultural industry convergence infancy, the tourism industry has shown a strong tendency to drive.

Suggestion. Tourism on the active integration of the cultural industry can provide a platform for the exchange of different cultures of the region, has become the carrier of cultural dissemination, protection and development of beneficial cultural resources. Therefore, the Government through the organization of different cultural festivals, exhibitions and cultural festival to promote tourism industry in the integration of the cultural industry initiative to achieve the protection of cultural 
resources, diversify the purpose of tourism resources. Multi-cultural resources is rich historical and cultural relics, has a natural attraction for tourists, as long as you can become slightly develop attractive tourism products. Cultural tourism enterprises by giving more resources to tourism function, so as to better meet the diverse needs of tourists, not only to promote the upgrading of the structure of the tourism industry, but also for the development of cultural industries another way.

Accommodation and catering industry provides accommodation and catering services for tourists. Cultural connotative accommodation and catering not only provides services for tourists, but also become tourist attraction tourism resources. Cave has a northern Shaanxi culture, Fujian Tulou is a combination of local cultural identity, while providing services for tourists, it has also become a tourist attraction travel tourism resources. Therefore, companies should be more conscious of cultural elements into the accommodation and catering industry. Travel industry during tourism product promotion, it can also make use of relevant techniques, cultural transmission to better achieve the effect of publicity.

The tourism industry and cultural industries in the primary stage of integration, the tourism industry reflects a strong leading role. On the status of this feature and the tourism industry without borders property and tourist demand for cultural products increasing. Tourism industry should take advantage of its industrial features, enhanced with higher levels of integration and cultural resources, will actively integrate into the current cultural elements into tourism products, thereby helping to create a number of high-end tourism representatives with Chinese culture, local cultural characteristics product.

\section{References}

[1] H.M. Wang. New Concept of Development of The Tourism Industry: 5C Mode. China Industrial Economy, 2007, (6): 13; 14; 18.

[2] M.Y. Luo. Interactive of Culture And Tourism of Fusion. Economic Issues, 2009, (9): 1.

[3] Y.W. Wu, X.N. Qing. Shanghai Tourism and Cultural Industries Fusion based on Tourist Behavior. Economic Forum, 2012, (3): 19-20

[4] J. Hu. Culture and Tourism Industry Research and Development. Shanxi Finance And Economics University, 2012,3 (34): 118.

[5] X.J. Huang. Q. Zhou. Industrial Integration based on Tourism and Cultural Industries Coordinated Development Countermeasures [J]. Tourism Economy, 2012, (9): 132

[6] H.Y. Zhang, Z.Y. Wang. Development Studies of Tourism Industry and Cultural Industry Convergence. Resource Development, 2010,26 (4): 325.

[7] L. Zhao. Tourism Industry and Cultural Industries Development of Fusion. Hefei: Anhui University Master's Degree Thesis, 2012.12; 19.

[8] H.Y. Zhang, Z.Y. Wang. Research Tourism Industry and Cultural Industry Convergence Mode of Operation. Shandong Social Science, 2009, (1): 171

[9] J. Yuan. Shenzhen Interactive Development Model of Tourism and Culture Industry. Tropical Geography, 2011, (1): 84-85.

[10] J. Yuan, H. Liu. Interactive Mode of Cultural Industries and Tourism Development. Reform And Strategy, 2011,27 (5): 125-126

[11] X.L. Cheng, Y.W. Zhu. Anhui Tourism Industry and Cultural Industry Development. Fusion Economic Geography, 2012,32 (9): 163-164

[12] P. Li, B.W. Li. Double-Nested Multivariate Fields Tourist Format Conceptual Model Preliminary Study. Tourism Tribune, 2012,27 (4): 66-67

[13] Fai, F. Tunzelmann, N. Industry-Specific Competencies and Converging Technologic Evidence from Patents. Structural Change and Economic Dynamics, 2001, (12).

[14] F. Li, T.Z. Chen, X. Xin. Study Evolutionary Relationships of the Tourism Industry and The Tourism Industry Structure. Fusion Tourism Tribune, 2013,28 (1): 72.

[15] Y. Xu, J. Sun. Integration of Information Industry and Manufacturing based on Research Performance Analysis. China Industrial Economy, 2009, (7): 58-59. 